\title{
ytiB and $y$ thA Genes Reduce the Uranium Removal Capacity of Bacillus atrophaeus
}

\author{
Li Wang ${ }^{1,2}$, Shiqi Xiao ${ }^{1}$, Xiaoming Chen ${ }^{1, *}$, , Shilin Chen ${ }^{3}$, Shanqiang Wang ${ }^{4}$, Chao Wang ${ }^{1}$, \\ Yunlai Tang ${ }^{1}$ and Faqin Dong ${ }^{1}$ \\ 1 School of Life Science and Engineering, Southwest University of Science and Technology, Mianyang 621010, \\ China; wangli@swun.edu.cn (L.W.); m18381654985_1@163.com (S.X.); w1870835752@sina.com (C.W.); \\ tyl@swust.edu.cn (Y.T.); fqdong@swust.edu.cn (F.D.) \\ 2 College of Life Science and Technology, Southwest Minzu University, Chengdu 610041, China \\ 3 Department of Bioengineering, University of California at Berkeley, CA 94703, USA; \\ alexchensl@berkeley.edu \\ 4 State Key Laboratory of NBC Protection for Civilian of China, Beijing 102205, China; 13651135504@163.com \\ * Correspondence: cxmxkd@163.com
}

Received: 25 January 2019; Accepted: 5 April 2019; Published: 10 April 2019

\begin{abstract}
Two Bacillus atrophaeus strains, the first being a highly stress-resistant ATCC 9372 strain and the Ua strain identified from a chromium mine by our lab, differ in their abilities to tolerate and remove Uranium (VI) from contaminated water. An increase in U(VI) concentration in growth media led to a decrease in the tolerance and bio-remedial capacity of both strains. However, under high concentrations of $\mathrm{U}(\mathrm{VI})$ in the growth media, the ATCC 9372 strain demonstrated a higher tolerance and a higher removal capacity than the Ua strain. Two approaches, transcriptome sequencing and transgenic technology, were used to elucidate the relationship between particular genes within these two strains and their $\mathrm{U}(\mathrm{VI})$ removal capacity. Sequencing confirmed the expression of two genes unique to the Ua strain, previously designated $y t i \mathrm{~B}$ and $y$ th $\mathrm{A}$. They encode putative proteins that show the highest levels of identity to carbonic anhydrase and cytochrome bd terminal oxidase I, respectively. Using the pBE-S DNA vector, $y t i B$ and $y t h A$ were transformed into the ATCC 9372 strain of Bacillus atrophaeus. Under a U(VI) concentration of $120 \mathrm{mg} / \mathrm{L}$, the removal rates of the transgenic ATCC 9372-ytiB and ATCC 9372-ythA strains decreased by $7.55 \%$ and $7.43 \%$, respectively, compared to the removal rate of the control strain transformed with empty plasmid. The results suggest that both $y$ th $\mathrm{A}$ and $y t i \mathrm{~B}$ genes have a negative influence on the uranium removing capacity of Bacillus atrophaeus. This finding will help to elucidate the molecular mechanisms of uranium removal by bacteria.
\end{abstract}

Keywords: Bacillus atrophaeus; gene $y$ th $\mathrm{A}$; Gene $y$ tiB; microbial remediation; uranium contamination

\section{Introduction}

Uranium is an important strategic and economic resource. Through the development of nuclear industry, nuclear technologies have expanded and are now used extensively in a variety of industrial productions, agriculture, energy production, military, transportation, and health care. Therefore, uranium contamination of soil and water has increased, resulting in serious human and animal diseases and an increased number of deaths [1]. Bioremediation was proposed as a plausible method for the removal of uranium contamination [2,3]. Microbial remediation is a promising technique for bioremediation. In this method microbes are used to either adsorb uranium or change the uranium oxidation state [4-6]. Differing abilities for microbial remediation of uranium pollution can be observed even among closely related strains of the same microbial species. The most likely explanation for this 
phenomenon would be the presence of unique gene(s) within the microbial genomes of particular strains. Therefore, revealing the differences between gene sets of closely related strains is an important way to understand the molecular mechanisms of bioremediation.

There are many methods that can be applied to reveal the differences between two organisms at the DNA, RNA or protein levels. Among them are the metagenomics library-based technique [7], gene chip technology [8], in-situ hybridization [9,10], western blot hybridization and transcriptome sequencing [11,12]. These methods provide high accuracy and high throughput, but there are also limitations specific to each method in relation to their practical application. The novel high-throughput deep sequencing technology has dramatically expanded the kinds of questions that can be answered and for strategies applied to study complex transcriptomes. This approach relies on the generation of featured EST tags corresponding to the fragments of the transcripts in a sample and their subsequent concatenation prior to cloning and sequencing [13]. Transcriptome analysis provides the ability to not only quantify the changes in expression levels for the same genes in different samples, but also to annotate the transcriptome and determine the structure of genes in the genome $[14,15]$. RNA sequencing has been exploited to analyze the dynamic transcriptome and abundance of specific bacterial genes [16-18].

The bacterial strain Bacillus subtilis var niger was re-classified as the ATCC 9372 strain of Bacillus atrophaeus by Nakamura in 1989 [19]. This strain can tolerate various adverse environments, such as high temperature, ultraviolet ionizing radiations, and toxic chemicals. Another strain of Bacillus atrophaeus found in a chromium mine and designated as Ua strain by our lab [20], is very similar to the ATCC 9372 strain, but it differs in its ability to tolerate and remove Uranium (VI). We proposed earlier that the possible reason for this phenomenon may be due to genetic differences between the strains. In our preliminary work, Pulsed Field Gel Electrophoresis (PFGE) was used to reveal differences between the genomes of Bacillus atrophaeus ATCC 9372 and Ua strains. DNA was digested by a combination of EcoRI and HindIII endonucleases, and a single DNA band that differed between the two strains was identified by PFGE. Sequencing of the DNA fragment isolated from this band revealed that the 3,128 bp long sequence contained $y$ th $\mathrm{A}$ and $y t i \mathrm{~B}$, genes, that were unique to the Ua strain [20].

In this work, transcriptome sequencing was used to verify gene sequences and to confirm that $y+i \mathrm{~B}$ and $y$ th $\mathrm{A}$ genes are expressed only in the Ua strain. Furthermore, a transgenic approach was applied to demonstrate the influence of these genes on the uranium removal capacity of Bacillus atrophaeus. The findings of this work will benefit further studies directed towards an understanding of the molecular mechanisms of uranium removal.

\section{Results and Discussion}

\subsection{Tolerance of ATCC 9372 and Ua Strains to Different Concentrations of U(VI)}

The growth curves of ATCC 9372 and Ua strains in TGY media containing different concentrations of U(VI) were shown in Figure 1. Better growth of ATCC 9372 strain compared to Ua strain in the medium containing the same $\mathrm{U}(\mathrm{VI})$ concentration demonstrated that this strain has a higher $\mathrm{U}(\mathrm{VI})$ tolerance than the Ua strain. The growth curve of ATCC 9372 strain reached its maximum $\mathrm{OD}_{600}$ value on $48 \mathrm{~h}$ after inoculation, and there was no significant change in ATCC 9372 growth dynamics in medium containing $80 \mathrm{mg} \mathrm{L}^{-1} \mathrm{U}(\mathrm{VI})$ compared to control medium having no uranium. However, a clear decrease in $\mathrm{OD}_{600}$ value was observed when the concentration of $\mathrm{U}(\mathrm{VI})$ in the growth medium was increased to $120 \mathrm{mg} \mathrm{L}^{-1}$. Similarly, the growth curve of the Ua strain reached its maximum $48 \mathrm{~h}$ after inoculation, and this strain had a high tolerance to uranium under $40 \mathrm{mg} \mathrm{L}^{-1} \mathrm{U}(\mathrm{VI})$. Increasing $\mathrm{U}(\mathrm{VI})$ concentration led to the decrease in growth rate for both strains; the highest $\mathrm{OD}_{600}$ values reached for ATCC 9372 and Ua strains (after $48 \mathrm{~h}$ of growth) decreased from 3.70 to 2.99 and 3.63 to 2.32 , respectively. 

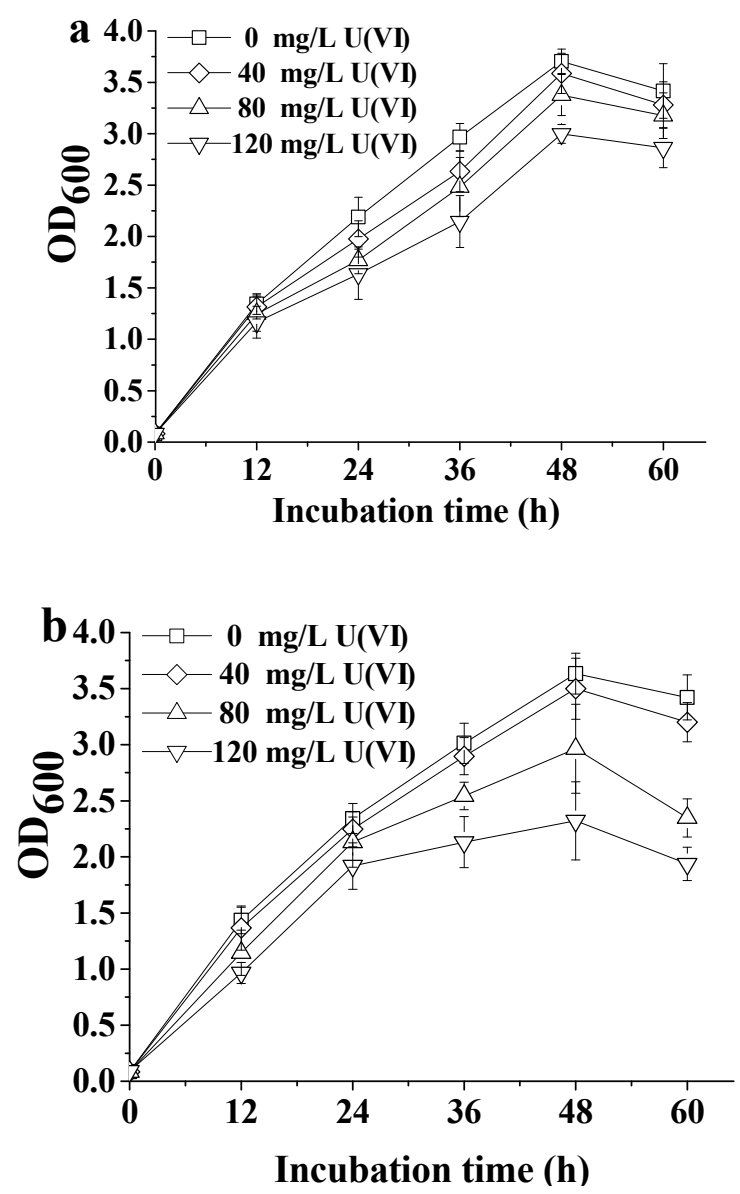

Figure 1. Growth dynamics of the ATCC9372 strain (a) and the Ua strain (b) in the U(VI) having growth media with different concentrations of uranium. All experiments were performed in triplicate. Average results of tree experiments were shown; bars represent standard deviations.

The removal capacities of U(VI) by ATCC 9372 and Ua strains were shown in Figure 2. At 40 and $80 \mathrm{mg} \mathrm{L}^{-1} \mathrm{U}(\mathrm{VI})$ the removal capacities of both strains were similar, reaching about $99 \%$ in $60 \mathrm{~h}$. However, at $120 \mathrm{mg} \mathrm{L}^{-1} \mathrm{U}(\mathrm{VI})$ the removal capacities of ATCC 9372 and Ua strains decreased to $93.33 \%$ and $72.18 \%$, respectively. In other words, the obtained results revealed that at high U(VI) concentrations the U(VI) removal capacity of ATCC 9372 strain was higher than that of the Ua strain.

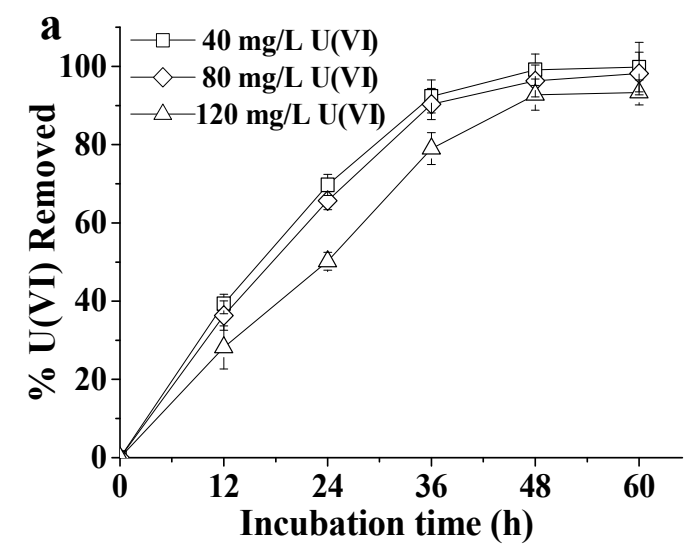

Figure 2. Cont. 


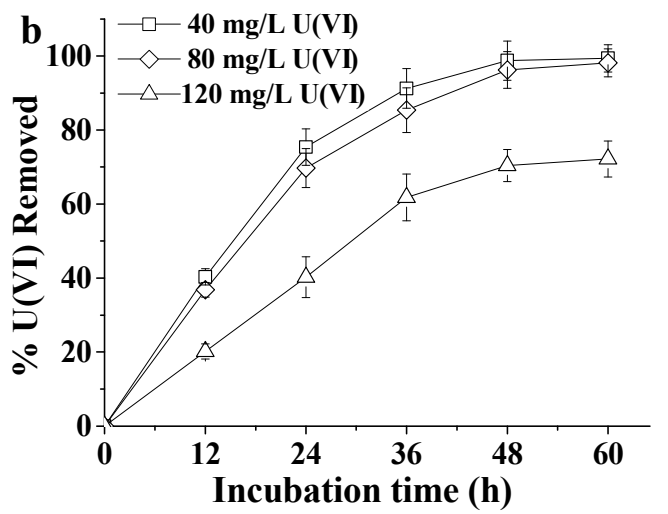

Figure 2. The U(VI) removal capacities of the ATCC 9372 strain (a) and the Ua strain (b). All experiments were performed in triplicate. The average results of three experiments were shown; bars represent standard deviations.

\subsection{Comparison of Bacillus atrophaeus Transcriptomes under Control Conditions and under Exposure to Uranium}

Raw RNA sequence reads were generated using Illumina HiSeq2500 equipment. After adapter clipping and quality trimming, clean reads were obtained for pools of total RNAs isolated from Bacillus atrophaeus ATCC 9372 and Ua strains, respectively. These clean reads were used in de novo assembly. The obtained contigs were assembled into unigenes after the splicing of sequences and the removing of redundancies. All clean reads for each group were compared to the genome of Bacillus atrophaeus 1942 strain (http:/ /www.ncbi.nlm.nih.gov/nuccore/310867486?report=fasta) (Table 1). In general, the ratio of mapping of all clean reads should show over $60 \%$ similarity with other strains of the same species. If the ratio is beyond 70\%, the two samples are considered to have high homology [21]. As shown in Table 1, both Bacillus atrophaeus strains, ATCC 9372 and Ua, showed high homology with Bacillus atrophaeus 1942. The unigenes from control and experimental samples were annotated by Gene Ontology (GO). All unigenes were divided into three main categories: (i) molecular functions, (ii) cellular components and (iii) biological processes. These three main categories in turn comprised more than 40 subcategories. In the biological process category, the single-organism and cellular processes were the most represented subcategories.

Table 1. The ratio statistics of Mapping.

\begin{tabular}{ccc}
\hline Group & Number of Clean Reads & Similarity (\%) \\
\hline ATCC 9372-0 & $22534064 / 28206904$ & $79.89 \%$ \\
ATCC 9372-U & $19228202 / 24475060$ & $78.56 \%$ \\
Ua-0 & $30370551 / 30654342$ & $99.10 \%$ \\
Ua-U & $39516637 / 40055216$ & $98.70 \%$ \\
\hline
\end{tabular}

Differentially expressed genes were analyzed using Kyoto Encyclopedia of Genes and Genomes (KEGG). A total of 8372 differentially expressed unigenes were acquired through comparisons between control gene expression and expression when exposed to $40 \mathrm{mg} / \mathrm{L} \mathrm{U}(\mathrm{VI})$. The comparison revealed 197 up-regulated and 196 down-regulated genes in the ATCC 9372 strain. However, 3793 genes did not show obvious changes in expression levels. 372 unigenes showed significant differential expression between the control and $\mathrm{U}(\mathrm{VI})$ groups of genes in the Ua strain, from which 228 genes were up-regulated and 144 genes were down-regulated. Analysis of these differentially expressed unigenes using $\mathrm{GO}$ database revealed that most of the regulated genes belonged to metabolic processes. This group of genes was followed by genes involved in catalytic activities, single-organism processes and proteolysis (Figures 3 and 4). 


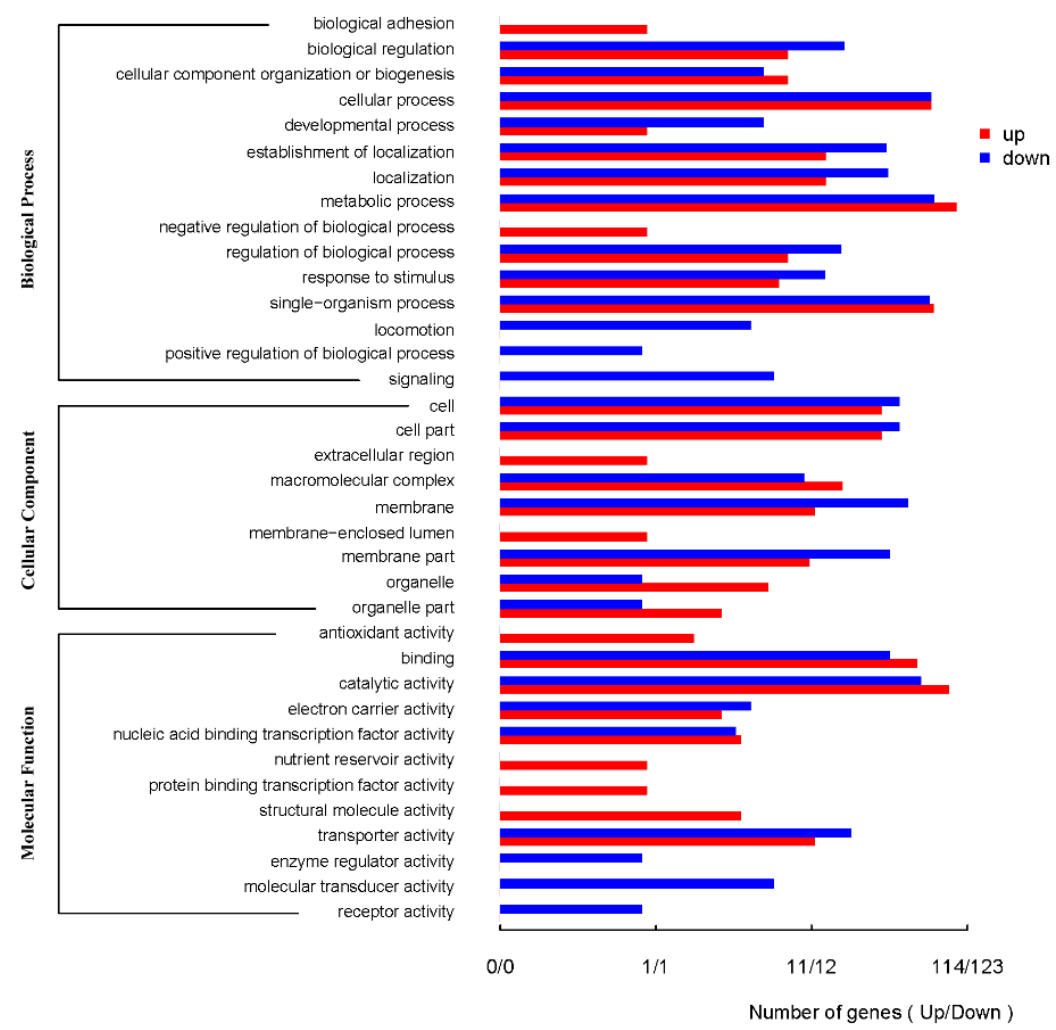

Figure 3. The GO annotations of differentially expressed genes of Bacillus atrophaeus ATCC 9372.
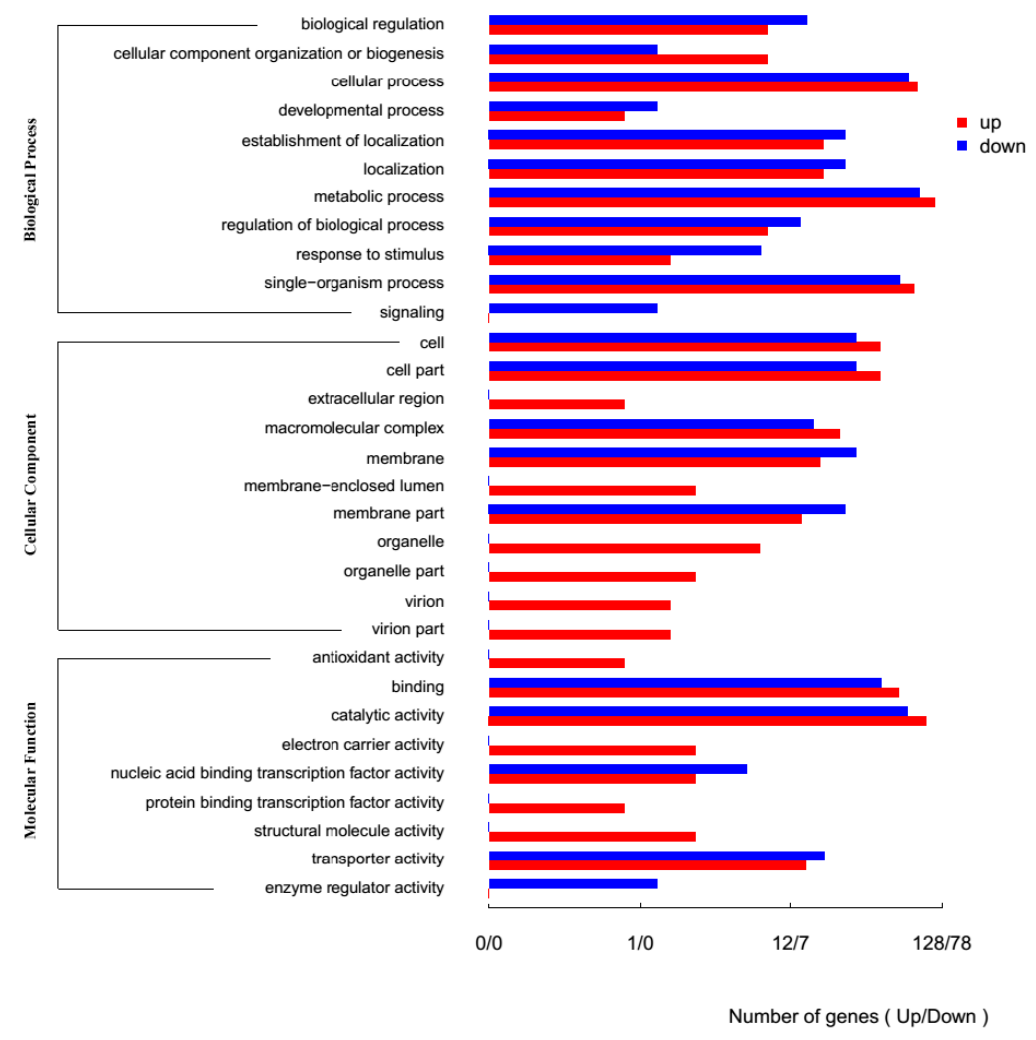

Figure 4. The GO annotations of differentially expressed genes of Bacillus atrophaeus Ua. 
Both ATCC 9372 and Ua strains belong to the same bacterial species of Bacillus atrophaeus, and therefore they are expected to have very similar genomic structures. However, their ability to tolerate high concentrations of uranium and their respective capacities to remove $\mathrm{U}(\mathrm{VI})$ from the growth media are distinctive. A difference in the gene sets contained within the genomes of the two strains is the most probable reason for their different phenotypes. Therefore, our first task was to identify a predicted small difference between the genomes of the two strains. Currently many methods exist to identify such differences through analysis of genomic DNA and/or sets of transcripts [17]. Most of these methods are expensive and/or need advanced operational skills. We selected the PFGE method to analyze the bacterial genomic DNA because it is relatively easy and cheap. PFGE is widely used for chromosomal DNA separation and electrophoretic karyotyping [22-24]. For analysis and comparison of the two bacterial transcriptomes, we applied high-throughput sequencing. RNA sequencing (RNA-seq) is a powerful tool for dissecting the relationships between genotypes and phenotypes, and a way to find differences between two transcriptomes. Free of many of the limitations that characterize other transcriptomic approaches, such as microarray and tag-based sequencing, RNA-seq has significantly changed the speed and accuracy of protokaryotic transcriptome analysis $[16,25]$.

\subsection{Isolation and Sequence Analysis of ytiB and ythA Genes}

$y t i \mathrm{~B}$ and $y$ th $\mathrm{A}$ genes were identified solely from the transcriptome sequencing results obtained for the Ua strain. In the KEGG database the $y t i B$ gene was present under the name CynT (Gene ID 2626) and the $y$ thA gene under the name CydA (Gene ID 2629). In the Non-redundant database, the $y t i B$ gene was predicted to encode carbonic anhydrase, while the $y$ th $\mathrm{A}$ was predicted to encode a subunit I of cytochrome bd terminal oxidase.

The nucleotide sequence of $y t i \mathrm{~B}$ cDNA was $570 \mathrm{bp}$ (GenBank accession no: MH142257) and contained an open reading frame of $564 \mathrm{bp}$, encoding a putative protein of 187 amino acids. The deduced molecular weight was $21.1 \mathrm{KDa}$ and predicted $\mathrm{pI}$ was 6.16. The ytiB protein contained a domain (29-181aa) characteristic to the beta-carbonic anhydrase clade and therefore belonged to the beta-carbonic anhydrase super family. Analysis using SigalIP 4.1 software revealed that the ytiB protein had no signal peptides but also did not belong to the list of non-secreted proteins. The predicted secondary structure of the ytiB protein consisted mainly of alpha helix $(48.13 \%)$, extended strand $(16.58 \%)$, beta turn $(8.02 \%)$ and random coiled sequence $(27.27 \%)$ structures. The predicted tertiary structure of the ytiB protein was modeled based on the template, which was a crystal structure of the 'cab' type beta class carbonic anhydrase from Methanobacterium thermoautotrophicum (PDB: 1g5c.1.A). The $y t i B$ protein had $37.04 \%$ identity to this 'cab' type beta class carbonic anhydrase. Phylogenetic analysis revealed that the $y t i B$ protein had the closest relationship to the carbonic anhydrase from Bacillus atrophaeus.

The nucleotide sequence of the $y$ thA cDNA was 1732 bp (GenBank accession no: MH142256) and contained an open reading frame of $1290 \mathrm{bp}$, encoding a putative protein of 429 amino acids. The deduced molecular weight of the protein was $47.7 \mathrm{KDa}$ and the predicted $\mathrm{pI}$ was 9.06 . The $y$ th A A protein had a domain named 'cytochrome bd terminal oxidase subunit I' (1-419 aa), which belonged to the cytochrome bd terminal oxidase I super family. SigalIP 4.1 showed that the $y$ th A protein had no signal peptides and was a non-secreted protein. The predicted secondary structure of the $y$ th $\mathrm{A}$ protein contained alpha helix structures $(49.18 \%)$, extended strand $(18.65 \%)$, beta turn $(4.20 \%)$ and random coiled sequence $(27.97 \%)$. The tertiary structure of the $y$ th $\mathrm{A}$ protein was modeled based on the template of the crystal structure of bd-type quinol oxidase subunit I from Geobacillus thermodenitrificans (PDB: 5doq.1.A). The $y$ th A protein possessed $43.13 \%$ identity to subunit I of the bd-type quinol oxidase. A rectangular phylogenetic tree was produced with the aim to assess the relationship of the $y$ th $\mathrm{A}$ protein to other known proteins. The yth protein belonged to the group of Bacillus atrophaeus, with cytochrome bd terminal oxidase subunit I grouped as the closest neighbor. 
Our previous study showed that $y t i \mathrm{~B}$ and $y$ th $\mathrm{A}$ genes were discovered only in the genome of the Ua strain [20]. In this study, transcript levels of $y t i B$ and $y$ th $A$ genes were calculated using the RSEM software. The results showed that the expression of both genes in the Ua strain were detectible after $48 \mathrm{~h}$ treatment with $40 \mathrm{mg} / \mathrm{L} \mathrm{U}(\mathrm{VI})$ (Table 2). The metabolic pathways of $y$ t $i \mathrm{~B}$ and $y$ th $\mathrm{A}$ gene products were analyzed using KEGG databases. It was found that $y t i \mathrm{~B}$ was involved in nitrogen metabolism, while $y$ thA was involved in oxidative phosphorylation and functioning of the two-component system. Since the metabolic pathways in which $y t i \mathrm{~B}$ and $y$ th $\mathrm{A}$ gene products were involved are very complex and included a large number of different proteins, it was impossible through use of bioinformatics alone to predict the interacting partners of these two proteins, which potentially could be responsible for the removal of uranium by Bacillus atrophaeus. Without further experiments, it was difficult at this stage to explain the molecular mechanisms behind the negative influence of $y t i \mathrm{~B}$ and $y$ th $\mathrm{A}$ on uranium removal capacity.

Table 2. The expression characteristics of $y t i \mathrm{~B}$ and $y$ th $\mathrm{A}$ genes.

\begin{tabular}{|c|c|c|c|c|c|c|c|c|}
\hline $\begin{array}{l}\text { Gene } \\
\text { ID }\end{array}$ & $\begin{array}{c}\text { String } \\
\text { Tophit } \\
\text { Description }\end{array}$ & $\begin{array}{l}\text { KEGG }_{-} \\
\text {Gene_- } \\
\text { Name }\end{array}$ & Length & $\begin{array}{c}\text { String }_{-} \\
\text {topHSP } \\
\text { \%-Simil }\end{array}$ & $\begin{array}{c}\mathrm{NR}_{-} \\
\text {tophit } \\
\text { Description }\end{array}$ & $\begin{array}{l}\text { Ua_0 } \\
\text { Count }\end{array}$ & $\begin{array}{l}\text { Ua_U } \\
\text { Count }\end{array}$ & $\begin{array}{l}\text { Up- or Down- } \\
\text { Regulation }\end{array}$ \\
\hline 2626 & $Y t i \mathrm{~B}$ & CynT & 570 & 95.72 & $\begin{array}{l}\text { carbonic anhydrase } \\
\text { cytochrome D }\end{array}$ & 294 & 281 & down \\
\hline 2629 & YthA & CydA & 1332 & 97.26 & $\begin{array}{l}\text { ubiquinol oxidase } \\
\text { subunit I }\end{array}$ & 350 & 256 & down \\
\hline
\end{tabular}

In our preliminary study, PFGE was applied to discover differences in the gene sets of ATCC 9372 and Ua genomes. The results showed that $y t i \mathrm{~B}$ and $y$ th $\mathrm{A}$ genes were present only in the Ua strain [20]. It was possible in our case to use PFGE to find differences between the two gene sets because of the high similarity of the studied organisms (two strains of the same species) and consequent similarity in their genomes. More experimental data will be required to decide if this method can be utilized for species that are more distally related. In addition, we had the good fortune that both genes were situated close to one another in the bacterial genome, on the same relatively large DNA fragment identified by PFGE. If $y t i \mathrm{~B}$ and $y$ th $\mathrm{A}$ were located in different parts of the bacterial genome and after restriction were situated on smaller DNA fragments, genes could be lost during PFGE, since small DNA fragments would quickly run off the gel.

Transcriptome sequencing enabled us to identify cDNA sequences of all transcribed genes and obtain their full-length sequences. The results obtained by transcriptome sequencing basically confirmed the result of PFGE comparison between ATCC 9372 and Ua strains. In that the two different transcribed genes, $y t i \mathrm{~B}$ and $y t h \mathrm{~A}$, were present only in the genome of the Ua strain. Transcriptome sequencing also provided corrections to the lengths of $y t i \mathrm{~B}$ and $y$ th $\mathrm{A}$ genes, which, according to the results of the genomic fragment sequencing were predicted to be $570 \mathrm{bp}$ and $1732 \mathrm{bp}$ long, respectively. The full-length sequence of the $y t i \mathrm{~B}$ cDNA was found to be $2 \mathrm{bp}$ longer and the $y$ th $\mathrm{A}$ cDNA was $339 \mathrm{bp}$ longer than the sequences predicted earlier based on genomic data [20]. Our data indicates that both PFGE and transcriptome sequencing were efficient in finding differences between two closely related microbial genomes. The availability of efficient and accurate technologies for gene discovery will be very useful in our future exploration of the molecular mechanisms of bacterial responses to environmental stimuli and stresses.

\subsection{Influence of $y t i B$ and $y$ th $A$ on the $U(V I)$ Removal Capacity of Bacteria in Transgenics}

The generation of transgenic strains using ATCC 9372 as the recipient strain was carried out as described in Materials and methods. Recombinant expression vectors were verified by restriction enzyme digestion with MluI and XbaI. The growth dynamics of ATCC 9372-ytiB and ATCC 9372-ythA transgenic strains and the ATCC 9372-S negative control strain, as well as their $\mathrm{U}(\mathrm{VI})$ removal capacity 
at $120 \mathrm{mg} \mathrm{L}^{-1}$ of $\mathrm{U}(\mathrm{VI})$ in the growth media are shown in Figure 5. All experiments were repeated three times, and averaged results were used in the figure.
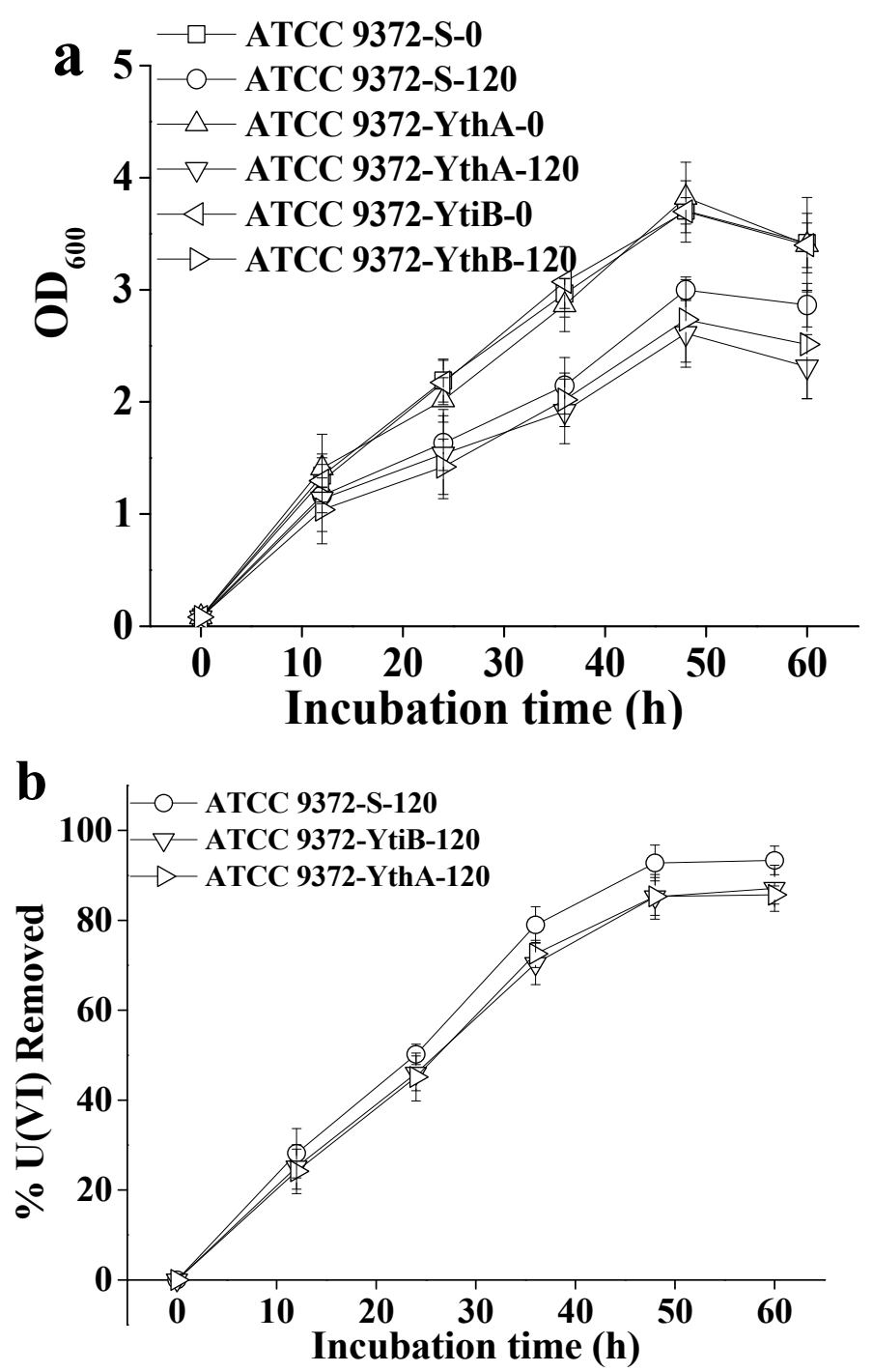

Figure 5. The growth rate (a) and U(VI) removal capacity (b) of transgenic ATCC 9372 strains in U(VI)-containing LB media. ATCC 9372-S-0 - the ATCC 9372 strain transformed with the pBE-S DNA and grown in the media containing no U(VI); ATCC 9372-S-120-the ATCC 9372 strain transformed with the pBE-S DNA and grown in the media containing $120 \mathrm{mg} \mathrm{L}^{-1} \mathrm{U}(\mathrm{VI})$; ATCC 9372-ytiB-0 — the ATCC 9372 strain transformed with the $y t i B$ gene and grown in the media containing no U(VI); ATCC 9372-ytiB-120 - the ATCC 9372 strain transformed with the $y t i \mathrm{~B}$ gene and grown in media containing $120 \mathrm{mg} \mathrm{L}^{-1} \mathrm{U}(\mathrm{VI})$; ATCC 9372-ythA-0 - the ATCC 9372 strain transformed with the $y$ thA gene grown in the media containing no U(VI); ATCC 9372-ythA-120 - the ATCC 9372 strain transformed with the $y$ th $\mathrm{A}$ gene grown in media containing $120 \mathrm{mg} \mathrm{L}^{-1} \mathrm{U}(\mathrm{VI})$. All experiments were performed in triplicate. The average results for three experiments are shown; bars represent standard deviations between repeats.

As is shown in Figure 5, transgenic ATCC 9372-S, ATCC 9372-ythA and ATCC 9372-ytiB strains as well as the wild type ATCC 9372 strain had no obvious differences in growth dynamics in the media containing $0 \mathrm{mg} \mathrm{L}^{-1} \mathrm{U}(\mathrm{VI})$. These data indicated that the transgenic manipulation did not produce any harmful changes to the original ATCC 9372 strain. The growth rate of ATCC 9372-ytiB strain decreased at the $\mathrm{U}(\mathrm{VI})$ concentration of $120 \mathrm{mg} \mathrm{L}^{-1}$. The uranium removal capacity of the ATCC 9372-S strain was equal to the control ATCC 9372 strain and higher than that of the ATCC 9372-ytiB strain ( $t$-test, 
$p<0.05)$. The U(VI) removal capacity of the ATCC 9372-S strain in the presence of $120 \mathrm{mg} \mathrm{L}^{-1} \mathrm{U}(\mathrm{VI})$ in the growth media was $92.77 \%$ on $48 \mathrm{~h}$ after inoculation. In contrast, the removal rate of ATCC 9372-ytiB strain was $85.22 \%$, which was very similar to the removal rate of the ATCC 9372-ythA strain. These results confirmed that the expression of each of the two genes tested has negative effects on the $\mathrm{U}(\mathrm{VI})$ removal capacity of the bacteria.

Analysis of gene function can be achieved through the generation of transgenic organisms with (i) expression of a transgene novel to the recipient organism, (ii) overexpression of a gene already existing in the recipient organism, or (iii) by application of gene knockout technologies [26,27]. In this study, the expression of transgenes was used to verify the influence of $y t i \mathrm{~B}$ and $y$ th $\mathrm{A}$ on the capacity of bacteria to remove uranium from solutions. To the best of our knowledge, no data on the involvement of $y t i \mathrm{~B}$ and $y$ th $\mathrm{A}$ genes in uranium removal has been published to date. The $y t i \mathrm{~B}$ gene encodes the carbonic anhydrase that catalyzes decomposition of carbonic acid into carbon dioxide and water $\left(\mathrm{HCO}^{3-}+\mathrm{H}^{+} \rightarrow \mathrm{CO}_{2}+\mathrm{H}_{2} \mathrm{O}\right)$ to help maintaining the $\mathrm{pH}$ balance of the cell [28]. The $y$ th $\mathrm{A}$ gene encodes cytochrome bd coenzyme oxidase that can be found in some kinds of azotobacters, and this coenzyme has the ability to remove or reduce oxygen as part of the electron transport chain. We have found that the expression of $y t i \mathrm{~B}$ and $y$ th $\mathrm{A}$ genes in the Ua strain was clearly suppressed after addition of even low concentrations of $\mathrm{U}(\mathrm{VI})$ to the growth media. There is obviously a negative correlation between the amount of $y t i \mathrm{~B}$ and $y$ th $\mathrm{A}$ gene products in bacteria and the concentration of the uranium in the bacterial growth media. It is therefore reasonable to speculate that suppression of $y t i \mathrm{~B}$ and $y t h \mathrm{~A}$ gene products with $\mathrm{U}(\mathrm{VI})$ negatively influenced the condition of the bacteria, making them less tolerant to stresses, including high concentrations of uranium, and, consequently, reduced their capacity to remove $\mathrm{U}(\mathrm{VI})$ from the media.

In this study, using transcriptome sequencing we were able to confirm that the previously identified $y t \mathrm{~B}$ and $y$ th $\mathrm{A}$ genes are present and expressed only in the Ua strain of Bacillus atrophaeus. Using transgenic technology, we introduced $y t i \mathrm{~B}$ and $y$ th A genes independently to the ATCC 9372 strain and demonstrated that the resulting phenotypes of the transgenic strains became very similar to the phenotype of the Ua strain; their capacity for uranium removal was reduced compared to the original wild type ATCC 9372 strain. Further investigations based on information collected by RNA sequencing should be focused on exploring the function of the genes, the regulation of their transcription by $\mathrm{U}(\mathrm{VI})$, and their roles in the molecular mechanisms of uranium removal by Bacillus atrophaeus.

\section{Materials and Methods}

\subsection{Microorganisms}

Bacillus atrophaeus ATCC 9372 strain was purchased from the Chinese General Microbiological Culture Collection (CGMCC) center. Bacillus atrophaeus Ua strain was isolated from a chromium mine by culturing in LB medium with $100 \mathrm{mg} \mathrm{L}^{-1} \mathrm{U}(\mathrm{VI})$. This strain is deposited into the CGMCC center under the strain number CGMCC 16080.

\subsection{Analysis of U(VI) Tolerance and Removal Capacities of Bacterial Strains}

ATCC 9372 and Ua strains were inoculated into $30 \mathrm{~mL}$ of TGY liquid medium (glucose $1.0 \mathrm{~g} \mathrm{~L}^{-1}$, tryptone $1.0 \mathrm{~g} \mathrm{~L}^{-1}$, yeast powder $3.0 \mathrm{~g} \mathrm{~L}^{-1}, \mathrm{pH} 7.0-7.2$ ), and incubated at $37^{\circ} \mathrm{C}$ for $18 \mathrm{~h}$ with constant shaking at $120 \mathrm{rpm}$. The $\mathrm{OD}_{600}$ value of each cell culture was adjusted to 0.8 with cell-free water, and then $10 \mathrm{~mL}$ of the inoculum was added to TGY liquid medium $(90 \mathrm{~mL})$ containing either $0 \mathrm{mg} \mathrm{L}^{-1}$, $40 \mathrm{mg} \mathrm{L}^{-1}, 80 \mathrm{mg} \mathrm{L}^{-1}$, or $120 \mathrm{mg} \mathrm{L}^{-1} \mathrm{U}(\mathrm{VI})$, respectively, and incubated at $37^{\circ} \mathrm{C}$ for $60 \mathrm{~h}$ with constant shaking at $120 \mathrm{rpm}$. All experimental treatments were run in triplicate. After a $10 \mathrm{~min}$ centrifugation at $10,000 \mathrm{rpm}$, the $\mathrm{OD}_{600}$ values of each medium and the $\mathrm{U}(\mathrm{VI})$ concentration in the supernatant, were measured after $0 \mathrm{~h}, 12 \mathrm{~h}, 24 \mathrm{~h}, 36 \mathrm{~h}, 48 \mathrm{~h}$, and $60 \mathrm{~h}$ of bacterial growth. Medium with the same U(VI) concentration, but without inoculum, was used as a negative control. The $\mathrm{OD}_{600}$ values were used to 
characterize the abilities of strains to tolerate $\mathrm{U}(\mathrm{VI})$, while $\mathrm{U}(\mathrm{VI})$ concentrations in the supernatant of media containing $120 \mathrm{mg} \mathrm{L}^{-1} \mathrm{U}(\mathrm{VI})$ were used to indicate the removal capacities of strains.

Content of $\mathrm{U}(\mathrm{VI})$ was determined by the arsenazo (III) staining method [29]. $1 \mathrm{~mL}$ of sample was added to $1 \mathrm{~mL}$ of arsenazo (III) chromogenic agent, the volume of the mix was adjusted to $10 \mathrm{~mL}$ with $0.4 \mathrm{~mol} / \mathrm{L}$ chloroacetic acid-sodium chloroacetate buffer, then the mix was shaken and left to incubate at room temperature for $30 \mathrm{~min}$. Absorbance at $652 \mathrm{~nm}$ was measured using a spectrophotometer and microbial medium was used as control.

\subsection{Total RNA Extraction and Transcriptome Sequencing}

Bacterial cultures were grown for $48 \mathrm{~h}$ after inoculation in $2 \mathrm{~mL}$ of the TGY media containing 0 and $40 \mathrm{mg} / \mathrm{L}$ uranium respectively. Total RNA was isolated from the ATCC 9372 and Ua strains using the RNAiso Plus Kit (Takara, Kyoto, Japan) according to the manufacturer's protocol. The quantities and integrities of RNAs were measured using Qubit and Agilent 2100 (ThermoFisher, Waltham, MA, USA). Transcriptome sequencing was carried out by Illumina HiSeq 2500 (Illumina, San Diego, CA, USA) according to the manufacturer's instructions. The adapters, low quality bases, and unknown bases were removed. The remaining clean reads were assembled using SeqPrep and Sickle software (https: //github.com/jstjohn/SeqPrep; https://github.com/najoshi/sickle). Unigenes from the de novo assembly were used for bioinformatics analysis. Unigenes were annotated using $\mathrm{Nr}$ (non-redundant protein sequences), Nt (non-redundant nucleotides), Pfam (Protein family), Swiss-Prot, GO (Gene Ontology database), Clusters of Orthologous Groups (COG) and KEGG (Kyoto Encyclopedia of Genes and Genomes) databases. Differentially expressed genes were analyzed using RSEM software (http://deweylab.biostat.wisc.edu/rsem/).

\subsection{Bioinformatic Analysis of $y$ tiB and $y$ thA Genes}

DNA traces were assembled with the Phred/Phrap/Consed package (http:/ /www.phrap.org). Sequence similarity analysis was performed using the BLAST program (http:/ / www.ncbi.nlm.nih. gov/blast). The open reading frames (ORF) were acquired with the help of the ORF Finder tool (http://www.ncbi.nlm.nih.gov/gorf/). Protein domains were determined by Interproscan (http: //www.ebi.ac.uk/interpro/) and signal peptides were identified by SignalP (http:/ / www.cbs.dtu.dk / services/SignalP/). The secondary structures of proteins were analyzed by SOPMA (https://npsaprabi.ibcp.fr/) and tertiary structures by SWISS-MODEL (http:/ / www.expasy.ch/swissmod/SWISSMODEL.html). Multiple sequence alignments were generated using Clustal $\mathrm{W}$ and phylogenetic trees constructed using the neighbor-joining method and the Mega 5.1 package. The reliability of the neighbor-joining tree was estimated by bootstrap analysis with 1000 repeats.

\subsection{Analysis of the Roles of $y$ tiB and $y$ thA in U(VI) Removal Using a Transgenic Approach}

In order to study the relationship between $y t i \mathrm{~B}$ and $y$ th $\mathrm{A}$ genes and the $\mathrm{U}(\mathrm{VI})$ removal capacity, the genes were transformed into the Bacillus atrophaeus ATCC 9372 strain. The primers used to amplify $y$ thA were: F: CGACGCGTGTGGATGATTTAGTTTTGG, R: GCTCTAGATTACGACTCC GCTGTATTTA, and for $y t i B$ were: F: CGACGCGTAGGGACAACGAACATGAGTCT, R: GCTCTA GAAGTCGATCCCGTTCCTGAAA. Initially, $y t i B$ and $y$ th A were cloned into the pEASY-T1 vector using E. coli DH5 $\alpha$ competent cells. Blue-White Screening was used to select transgenic E. coli $\mathrm{DH} 5 \alpha$ colonies. The recombinant plasmids were isolated from the selected transgenic E. coli $\mathrm{DH} 5 \alpha$ strains and digested with $M l u \mathrm{I}$ and $\mathrm{X} b a \mathrm{I}$ endonucleases. Fragments containing $y t i \mathrm{~B}$ and $y$ th $\mathrm{A}$ genes were detected by electrophoresis and the corresponding bands were purified from the Agarose gel. The purified DNA fragments were ligated into the $M l u \mathrm{I}$ and $\mathrm{XbaI}$ restriction sites of the recombinant pBE-S DNA expression vector. The resulting plasmids and empty vectors were transformed into the Bacillus atrophaeus ATCC 9372 strain, which did not contain ytiB and ythA genes. Ampicillin was used for the selection of transformed cells. The transgenic strain expressing the $y t i \mathrm{~B}$ transgene was designated as ATCC 9372-ytiB strain, and the transgenic strain expressing $y$ th $\mathrm{A}$ transgene was named as 
ATCC 9372-ythA strain. The transgenic strain containing the empty pBE-S DNA vector was designated as ATCC 9372-S and used as the control. The tolerance of transgenic strains to high concentrations of $\mathrm{U}(\mathrm{VI})$ as well as their $\mathrm{U}(\mathrm{VI})$ removal capacities were evaluated as described previously. $T$-test was used to analyze the significant differences between two data.

Author Contributions: Conceptualization, X.C.; Methodology, S.X., C.W. and S.W.; Software, Y.T.; Validation, S.C.; Manuscript writing, L.W.; Funding acquisition, X.C. and F.D.

Funding: This study was supported by the Major State Development Program of China (973 Program, Grant No. 2014CB846003), the National Defense Science and Technology Foundation of China (Grant No. 16ZG6101), State Key Laboratory Foundation of NBC Protection for Civilian of China (Grant No. SKLNBC2015-04), Sichuan Province Foundation (Grant No. 18YYJC0927).

Conflicts of Interest: The authors declare no conflict of interest. The funders had no role in the design of the study; in the collection, analyses, or interpretation of data; in the writing of the manuscript, or in the decision to publish the results.

\section{References}

1. Nair, R.N.; Faby, S.; Manikandan, S.T. Modelling of decay chain transport in groundwater from uranium tailings ponds. Appl. Math. Model. 2010, 34, 2300-2311. [CrossRef]

2. Teixeira, S.; Vieira, M.N.; Marques, J.E.; Pereira, R. Bioremediation of an iron-rich mine effluent by Lemna minor. Int. J. Phytorem. 2014, 16, 1228-1240. [CrossRef] [PubMed]

3. Zhou, Y.Y.; Tang, L.; Zeng, G.M.; Chen, J.; Cai, Y.; Zhang, Y.; Yang, G.D.; Liu, Y.Y.; Zhang, C.; Tang, W.W. Mesoporous carbon nitride based biosensor for highly sensitive and selective analysis of phenol and catechol in compost bioremediation. Biosens. Bioelectron. 2014, 61, 519-525. [CrossRef] [PubMed]

4. Shi, L.; Dong, H.L.; Reguera, G.; Beyenal, H.; Lu, A.H.; Liu, J.; Yu, H.Q.; Fredrickson, J.K. Extracellular electron transfer mechanisms between microorganisms and minerals. Nat. Rev. Microbiol. 2016, 14, 651-662. [CrossRef]

5. Zammit, C.M.; Shuster, J.P.; Gagen, E.J; Southam, G. The geomicrobiology of supergene metal deposits. Elements 2015, 11, 337-342. [CrossRef]

6. Ortiz-Bernad, I.; Anderson, R.T.; Vrionis, H.A.; Lovley, D.R. Resistance of Solid-Phase U(VI) to Microbial Reduction during In Situ Bioremediation of Uranium-Contaminated Groundwater. Appl. Environ. Microbiol. 2004, 70, 7558-7560. [CrossRef] [PubMed]

7. Skennerton, C.T.; Barr, J.J; Slater, F.R.; Bond, P.L.; Tyson, G.W. Expanding our view of genomic diversity in Candidatus Accumulibacter clades. Environ. Microbiol. 2015, 17, 1574-1585. [CrossRef] [PubMed]

8. Luo, M.Y.; Tian, Z.G.; Xu, Z.; Zhang, L.; Wang, Y.X.; Chen, J. Construction and application of a micro-array for profiling micro-RNA expression. Prog. Biochem. Biophys. 2007, 34, 31-41.

9. Wright, E.S.; Yilmaz, L.S.; Corcoran, A.M.; Okten, H.E.; Noguera, D.R. Automated design of probes for rRNA-targeted fluorescence in situ hybridization reveals the advantages of using dual probes for accurate identification. Appl. Environ. Microbiol. 2014, 80, 5124-5133. [CrossRef]

10. Murai, J.; Marchand, C.; Shahane, S.A.; Sun, H.M.; Huang, R.L.; Zhang, Y.P.; Chergui, A.; Ji, J.P; Doroshow, J.H.; Jadhav, A. Identification of novel PARP inhibitors using a cell-based TDP1 inhibitory assay in a quantitative high-throughput screening platform. DNA Repair 2014, 21, 177-182. [CrossRef] [PubMed]

11. Han, L.L.; Shao, H.H.; Liu, Y.C.; Liu, G.; Xie, C.Y.; Cheng, X.J.; Wang, H.Y.; Tan, X.M.; Feng, H. Transcriptome profiling analysis reveals metabolic changes across various growth phases in Bacillus pumilus BA06. BMC Microbiol. 2017, 17, 156. [CrossRef]

12. Liu, S.; Hao, H.; Lu, X.; Zhao, X.; Wang, Y.; Zhang, Y.; Xie, Z.; Wang, R. Transcriptome profiling of genes involved in induced systemic salt tolerance conferred by Bacillus amyloliquefaciens FZB42 in Arabidopsis thaliana. Sci. Rep. 2017, 7, 10795. [CrossRef]

13. Fullwood, M.J.; Wei, C.L.; Liu, E.T.; Ruan, Y. Next-generation DNA sequencing of paired-end tags (PET) for transcriptome and genome analyses. Genome Res. 2009, 19, 521-532. [CrossRef]

14. Lim, J.H.; Han, Y.J.; Kim, H.J.; Kwak, D.W.; Park, S.Y.; Chun, S.H.; Ryu, H.M. Genome-wide gene expression analysis in the placenta from fetus with trisomy 21. BMC Genom. 2017, 18, 720. [CrossRef] 
15. Leimena, M.M.; Wels, M.; Bongers, R.S.; Smid, E.J.; Zoetendal, E.G.; Kleerebezem, M. Comparative Analysis of Lactobacillus plantarum WCFS1 Transcriptomes by Using DNA Microarray and Next-Generation Sequencing Technologies. Appl. Environ. Microbiol. 2012, 78, 4141-4148. [CrossRef]

16. McKenzie, A.T.; Pomerantsev, A.P.; Sastalla, I.; Martens, C.; Ricklefs, S.M.; Virtaneva, K.; Anzick, S.; Porcella, S.F.; Leppla, S.H. Transcriptome analysis identifies Bacillus anthracis genes that respond to $\mathrm{CO}_{2}$ through an AtxA-dependent mechanism. BMC Genom. 2014, 15, 229. [CrossRef]

17. Xie, S.; Wu, H.; Chen, L.; Zang, H.; Xie, Y.; Gao, X. Transcriptome profiling of Bacillus subtilis OKB105 in response to rice seedlings. BMC Microbiol. 2015, 15, 21. [CrossRef]

18. Liu, X.; Yang, H.; Zheng, J.; Ye, Y.; Pan, L. Identification of strong promoters based on the transcriptome of Bacillus licheniformis. Biotechnol Lett. 2017, 39, 873-881. [CrossRef]

19. Nakamura, L.K. Taxonomic Relationship of Black-Pigmented Bacillus subtilis Strains and a Proposal for Bacillus atrophaeus sp. nov. Int. J. Syst. Bacteriol. 1989, 39, 295-300. [CrossRef]

20. Wang, C.; Chen, X.M.; Xu, Y.; Ruan, C.; Liu, X.L.; Hao, X.C.; Song, S.; Luo, X.G.; Chen, C.X.; Luo, Y.X. Analyzation on Genetic Variations Associated With Cr(VI) Removal Between two Bacillus atrophaeus Strains Applied PFGE Technology. J. Nucl. Agricul. Sci. 2015, 29, 1052-1060.

21. Martin, J.A.; Wang, Z. Next-generation transcriptome assembly. Nat. Rev. Genet. 2011, 12, 671-682. [CrossRef]

22. Chiou, C.S.; Torpdahlb, M.; Liao, Y.S.; Liao, C.H.; Tsao, C.S.; Liang, S.Y.; Wang, Y.W.; Kuo, J.C.; Liu, Y.Y. Usefulness of pulsed-field gel electrophoresis profiles for the determination of Salmonella serovars. Int. J. Food Microbiol. 2015, 214, 1-3. [CrossRef]

23. Azimi, L.; Talebi, M.; Khodaei, F.; Najafi, M.; Lari, A.R. Comparison of multiple-locus variable-number tandem-repeat analysis with pulsed-field gel electrophoresis typing of carbapenemases producing Acinetobacter baumannii isolated from burn patients. Burns 2015, 42, 441-445. [CrossRef]

24. Bopp, D.J.; Baker, D.J.; Thompson, L.; Saylors, A.; Root, T.P.; Armstrong, L.; Mitchell, K.; Dumas, N.B.; Musser, K.A. Implementation of Salmonella serotype determination using pulsed-field gel electrophoresis in a state public health laboratory. Diagn. Micr. Infec. Dis. 2016, 85, 416-418. [CrossRef]

25. Bassi, D.; Colla, F.; Gazzola, S.; Puglisi, E.; Delledonne, M.; Cocconcelli, P.S. Transcriptome analysis of Bacillus thuringiensis spore life, germination and cell outgrowth in a vegetable-based food model. Food Microbiol. 2016, 55, 73-85. [CrossRef]

26. Misture, S.T.; Naylor, M.O.; Jin, T.; Shelby, J.E. Galliosilicate glasses for viscous sealants in solid oxide fuel cell stacks: Part II: Interactions with yttria stabilized zirconia and stainless steel coated with alumina. Int. J. Hydrogen. Energ. 2013, 38, 16328-16337. [CrossRef]

27. Draberova, L.; Bugajev, V.; Potuckova, L.; Halova, I.; Bambouskova, M.; Polakovicova, I.; Xavier, R.J.; Seed, B.; Draber, P. Transmembrane adaptor protein PAG/CBP is involved in both positive and negative regulation of mast cell signaling. Mol. Cell Biol. 2014, 34, 4285-4300. [CrossRef]

28. Barbe, V.; Cruveiller, S.; Kunst, F.; Lenoble, P.; Meurice, G.; Sekowska, A.; Vallenet, D.; Wang, T.; Moszer, I.; Medigue, C.; Danchin, A. From a consortium sequence to a unified sequence: The Bacillus subtilis 168 reference genome a decade later. Microbiol 2009, 155, 1758-1775. [CrossRef]

29. Jauberty, L.; Drogat, N.; Decossas, J.L.; Delpech, V.; Vincent, G.; Sol, V. Optimization of the arsenazo-III method for the determination of uranium in water and plant samples. Talanta 2013, 115, 751-754. [CrossRef] 